\title{
Comparison of extracorporeal membrane oxygenation outcome for influenza- associated acute respiratory failure in Japan between 2009 and 2016
}

Shinichiro Ohshimo ${ }^{1}$, Nobuaki Shime ${ }^{1 *}$, Satoshi Nakagawa ${ }^{2}$, Osamu Nishida ${ }^{3}$, Shinhiro Takeda ${ }^{4}$ and Committee of the Japan ECMO project

\begin{abstract}
Background: Since the 2009 pandemic influenza, we have nationally established a committee of the extracorporeal membrane oxygenation (ECMO) project. This project involves adequate respiratory management for severe respiratory failure using $\mathrm{ECMO}$. This study aimed to investigate the correlations between changes in respiratory management using ECMO in Japan and outcomes of patients with influenza-associated acute respiratory failure between 2009 and 2016.

Methods: We investigated the incidence, severity, characteristics, and prognosis of influenza-associated acute respiratory failure in 2016 by web-based surveillance. The correlations between clinical characteristics, ventilator settings, ECMO settings, and prognosis were evaluated.

Results: A total of 14 patients were managed with ECMO in 2016. There were no significant differences in age, sex, and the acute physiology and chronic health evaluation II score between 2009 and 2016. The maximum sequential organ failure assessment score and highest positive end-expiratory pressure were lower in 2016 than in 2009 ( $p=0.03$ and $p=0.015$, respectively). Baseline and lowest partial pressure of arterial oxygen $\left(\mathrm{PaO}_{2}\right) /$ fraction of inspiratory oxygen $\left(\mathrm{F}_{1} \mathrm{O}_{2}\right)$ ratios were higher in 2016 than in 2009 ( $p=0.009$ and $p=0.002$, respectively). The types of consoles, circuits, oxygenators, centrifugal pumps, and cannulas were significantly changed between 2016 and 2009 ( $p=0.006, p=0.003$, $p=0.004, p<0.001$, respectively). Duration of the use of each circuit was significantly longer in 2016 than in 2009 (8.5 vs. 4.0 days; $p=0.0001$ ). Multivariate analysis showed that the use of ECMO in 2016 was an independent predictor of better overall survival in patients with influenza-associated acute respiratory failure (hazard ratio, $7.25 ; 95 \%$ confidence interval, 1.35-33.3; $p=0.021$ ).

Conclusions: Respiratory management for influenza-associated acute respiratory failure using ECMO was significantly changed in 2016 compared with 2009 in Japan. The outcome of ECMO use had improved in 2016 compared with the outcome in 2009 in patients with influenza-associated acute respiratory failure.
\end{abstract}

Keywords: Acute respiratory distress syndrome, Mechanical ventilation, Prognosis, Survival, Complication

\footnotetext{
* Correspondence: nshime@hiroshima-u.ac.jp

${ }^{1}$ Department of Emergency and Critical Care Medicine, Graduate School of

Biomedical and Health Sciences, Hiroshima University, 1-2-3 Kasumi,

Minami-ku, Hiroshima 734-8551, Japan

Full list of author information is available at the end of the article
}

(c) The Author(s). 2018 Open Access This article is distributed under the terms of the Creative Commons Attribution 4.0 International License (http://creativecommons.org/licenses/by/4.0/), which permits unrestricted use, distribution, and reproduction in any medium, provided you give appropriate credit to the original author(s) and the source, provide a link to the Creative Commons license, and indicate if changes were made. The Creative Commons Public Domain Dedication waiver (http://creativecommons.org/publicdomain/zero/1.0/) applies to the data made available in this article, unless otherwise stated. 


\section{Background}

Influenza virus can occasionally induce severe respiratory failure, including acute respiratory distress syndrome. The Centers for Disease Control and Prevention reported that more than approximately 20,000 influenza-associated deaths annually occurred in the USA [1]. Extracorporeal membrane oxygenation (ECMO) can be a lifesaving method in patients with potentially reversible acute respiratory failure, including influenza-associated acute respiratory failure $[2,3]$. However, Takeda et al. showed that the survival rate of influenza-associated acute respiratory failure managed with ECMO in Japan was inferior compared with that in other countries during the pandemic of $\mathrm{H} 1 \mathrm{~N} 1$ influenza in 2009 [4-6]. Inadequate use of ECMO equipment (cannula, pump, and oxygenator), insufficient understanding of the ECMO strategy by physicians and other medical staff, and insufficient centralization of ECMO treatment might have affected this poor survival rate in Japan [4].

Since the 2009 pandemic of H1N1 influenza, we have nationally established a committee of an ECMO project, which is expected to guide adequate respiratory management for severe respiratory failure using ECMO. Introduction and simulation education by the ECMO project includes the physiology of ECMO, cannulation techniques, repositioning of the cannula, monitoring skill, daily management, and troubleshooting.

This study aimed to investigate the incidence, severity, characteristics, and prognosis of pandemic of influenza-associated acute respiratory failure that occurred in Japan in 2016. We also aimed to evaluate the correlations between changes in respiratory management using ECMO and outcomes of patients with influenza-associated acute respiratory failure in 2009 and 2016.

\section{Methods}

This study involved adult patients with acute respiratory failure that was associated with $\mathrm{H} 1 \mathrm{~N} 1$ influenza who were admitted to the institutes of the ECMO project from January to April in 2016. A database was created based on the information collected from the institutes that participated in this study. A total of 87 institutes participate in the ECMO project, and 463 patients with various kind of respiratory failure who underwent ECMO have been registered in the database. Among them, 14 patients in 2009 and 14 patients in 2016 who suffered from influenza-associated acute respiratory failure were analyzed in this study. Data extracted from a previous study [4] were simultaneously analyzed and compared with those in the ECMO 2016 group. Informed consent was obtained from each individual by document or the opt-out procedure. Collected data included baseline characteristics (age, sex, body weight, body temperature, acute physiology and chronic health evaluation [APACHE] II score, and predicted death rate), sequential organ failure assessment (SOFA) score, administered drugs, ventilator settings, ECMO equipment and settings, and outcome. Maximum SOFA score was defined as the highest SOFA score before starting ECMO. Overall survival rate was defined as the survival rate during the follow-up. Inclusion criteria were as follows: (1) patients with influenza-associated acute respiratory failure who were treated in institutes that participated in the ECMO project and (2) age older than 20 years. Categorical differences between the survival and non-survival groups were compared using Fisher's exact test or the chi-square test. Numerical differences were compared using the Mann-Whitney $U$ test. Multivariate analysis was conducted after adjustment for the predicted death rate. All statistical analyses were performed using SPSS software (Abacus Concepts, Berkeley, CA, USA). All values are reported as median (interquartile), and all $p$ values less than 0.05 were considered statistically significant. This study was approved by the ethical committee in Hiroshima University with the approval number of E-390-1. Each institute obtained institutional ethics approval and consent to participate.

\section{Results}

\section{Patients' characteristics}

A total of 14 patients from 16 institutes participating in ECMO project were enrolled as the ECMO 2016 group in this study (Table 1). There were no significant differences in age, sex, weight, body mass index, and APACHE II score between the groups. Maximum SOFA scores in the ECMO 2016 group were significantly lower than those in the ECMO 2009 group. (ECMO 2009 group, 16 [12-19]; ECMO 2016 group, 11 [9-13]; $p=0.030$ ). There were no significant differences in the underlying conditions, complications, and the use of rescue and adjunctive therapies (prone positioning, renal replacement therapy, non-invasive positive pressure ventilation) between the groups. The use of peramivir was significantly increased, and the use of oseltamivir was significantly decreased in 2016 compared with 2009. The baseline pressure of arterial oxygen/fraction of inspiratory oxygen ratio (80 vs $55 ; p=0.009$ ) and the lowest pressure of arterial oxygen/fraction of inspiratory oxygen ratio (70 vs 50; $p=0.002$ ) were higher in 2016 compared with 2009. The highest positive end-expiratory pressure was lower in 2016 compared with 2009 (15 vs $24 \mathrm{cmH}_{2} \mathrm{O}$; $p=0.015)$. The lowest compliance in 2016 was 31 (9-42) $\mathrm{mL} / \mathrm{cmH}_{2} \mathrm{O}$.

\section{Changes in ECMO equipment}

There were significant changes in the proportions of the console, circuit, oxygenator, and centrifugal pump between 2009 and 2016. The ECMO equipment models used in 2016 widely varied, whereas those in 2009 were almost 
Table 1 Baseline characteristics of the patients enrolled

\begin{tabular}{|c|c|c|c|}
\hline Year & 2009 & 2016 & $p$ value \\
\hline$n$ & 14 & 14 & \\
\hline Age & $54(43-60)$ & $52(43-63)$ & 0.70 \\
\hline Sex (male/female) & $12 / 2$ & $12 / 2$ & $>0.99$ \\
\hline Weight (kg) & $70(64-80)$ & $67(59-78)$ & 0.50 \\
\hline $\mathrm{BMI}$ & NA & $23(22-27)$ & \\
\hline \multicolumn{4}{|l|}{ Body temperature $\left({ }^{\circ} \mathrm{C}\right)$} \\
\hline On admission & $38.8(37.1-39.1)$ & $37.5(36.7-38.2)$ & 0.11 \\
\hline Maximum & $39.4(38.7-39.8)$ & $38.2(37.7-39.7)$ & 0.21 \\
\hline APACHE II score & $17(12-25)$ & $20(5-37)$ & 0.30 \\
\hline Predicted death rate (\%) & $24.9(14.6-54.1)$ & $38.0(34.5-47.8)$ & 0.24 \\
\hline Maximum SOFA score & $16(12-19)$ & $11(9-13)$ & 0.030 \\
\hline \multicolumn{4}{|l|}{ Underlying condition } \\
\hline Immunosuppression & $0(0)$ & $3(21)$ & 0.22 \\
\hline Drug abuse & $1(7)$ & $0(0)$ & $>0.99$ \\
\hline Pregnancy & $1(7)$ & $0(0)$ & $>0.99$ \\
\hline COPD & $0(0)$ & $2(14)$ & 0.46 \\
\hline Chronic renal failure & $0(0)$ & $2(14)$ & 0.46 \\
\hline Vaccination & $1(7)$ & $1(7)$ & $>0.99$ \\
\hline Influenza antigen/PCR (A/B) & $14 / 0$ & $14 / 0$ & $>0.99$ \\
\hline \multicolumn{4}{|l|}{ Complications } \\
\hline Acute renal failure & $7(50)$ & $9(64)$ & 0.70 \\
\hline Acute hepatic failure & $4(29)$ & $1(7)$ & 0.32 \\
\hline Culture-confirmed infection & $5(36)$ & $10(71)$ & 0.13 \\
\hline Shock & $4(29)$ & $5(36)$ & $>0.99$ \\
\hline Cardiac failure & $0(0)$ & $0(0)$ & $>0.99$ \\
\hline Respiratory failure & $1(7)$ & $2(14)$ & $>0.99$ \\
\hline Neurological impairment & $0(0)$ & $0(0)$ & $>0.99$ \\
\hline \multicolumn{4}{|l|}{ Medical treatment } \\
\hline Peramivir & $5(36)$ & $14(100)$ & 0.001 \\
\hline Oseltamivir & $6(43)$ & $0(0)$ & 0.021 \\
\hline Zanamivir & $1(7)$ & $1(7)$ & $>0.99$ \\
\hline Laninamivir & $0(0)$ & $0(0)$ & $>0.99$ \\
\hline Antibiotics & $13(93)$ & $13(93)$ & $>0.99$ \\
\hline gamma-globulin & $5(36)$ & $3(21)$ & 0.68 \\
\hline \multicolumn{4}{|l|}{ Corticosteroid } \\
\hline High-dose methylprednisolone & $9(64)$ & $6(43)$ & 0.45 \\
\hline Low dose & $7(50)$ & $6(43)$ & $>0.99$ \\
\hline Sivelestat & $5(36)$ & $1(7)$ & 0.17 \\
\hline Vasoactive drugs & $13(93)$ & $11(79)$ & 0.24 \\
\hline \multicolumn{4}{|l|}{ Rescue and adjunctive therapies } \\
\hline Prone & $3(21)$ & $5(36)$ & 0.68 \\
\hline Nitric oxide & $1(7)$ & $2(14)$ & $>0.99$ \\
\hline CRRT & $7(50)$ & $7(50)$ & $>0.99$ \\
\hline
\end{tabular}


Table 1 Baseline characteristics of the patients enrolled (Continued)

\begin{tabular}{|c|c|c|c|}
\hline Year & 2009 & 2016 & $p$ value \\
\hline HFOV & $0(0)$ & $0(0)$ & $>0.99$ \\
\hline APRV & $13(93)$ & $5(36)$ & 0.006 \\
\hline NPPV & $3(21)$ & $4(29)$ & $>0.99$ \\
\hline \multicolumn{4}{|l|}{ Respiratory impairment before starting ECMO } \\
\hline $\mathrm{PaO}_{2} / \mathrm{F}_{1} \mathrm{O}_{2}$ before starting ventilation & $55(46-65)$ & $80(64-80)$ & 0.009 \\
\hline $\mathrm{PaO}_{2} / \mathrm{F}_{1} \mathrm{O}_{2}$ at starting ventilation & $78(58-86)$ & $96(72-150)$ & 0.09 \\
\hline Lowest $\mathrm{PaO}_{2} / \mathrm{F}_{1} \mathrm{O}_{2}$ during ventilation & $50(41-52)$ & $70(58-75)$ & 0.002 \\
\hline PEEP at starting ventilation $(\mathrm{cmH} 2 \mathrm{O})$ & $10(10-11)$ & $11(8-14)$ & 0.48 \\
\hline Highest PEEP during ventilation $\left(\mathrm{cmH}_{2} \mathrm{O}\right)$ & $24(17-30)$ & $15(14-19)$ & 0.015 \\
\hline PIP at starting ventilation $\left(\mathrm{cmH}_{2} \mathrm{O}\right)$ & $25(21-29)$ & $21(18-27)$ & 0.17 \\
\hline Highest PIP during ventilation $\left(\mathrm{cmH}_{2} \mathrm{O}\right)$ & $30(30-34)$ & $28(25-30)$ & 0.10 \\
\hline Ol at starting ventilation & NA & $16(3-21)$ & \\
\hline Highest OI during ventilation & NA & $20(8-27)$ & \\
\hline
\end{tabular}

Data are expressed as median (interquartile) or number (\%)

$B M I$ body mass index, APACHE acute physiology and chronic health evaluation, SOFA sequential organ failure assessment, COPD chronic obstructive pulmonary disease, $P C R$ polymerase chain reaction, DIC disseminated intravascular coagulation; CRRT continuous renal replacement therapy, HFOV high-frequency oscillatory ventilation, $A P R V$ airway pressure release ventilation, $\mathrm{NPPV}$ non-invasive positive pressure ventilation, $E C M O$, extracorporeal membrane oxygenation, $\mathrm{PaO} \mathrm{O}_{2} / \mathrm{FIO}_{2}$ pressure of arterial oxygen/fraction of inspiratory oxygen ratio, PEEP positive end-expiratory pressure, PIP peak inspiratory pressure, OI oxygenation index, ICU intensive care unit, NA not available

homogeneous. The diameters of drainage and return cannulas were significantly larger in 2016 compared with 2009 ( $p=0.0097, p=0.022$, respectively; Fig. 1 ). The durations of each circuit were 4.0 (3.3-4.9) days in 2009, and $8.5(6.5-14.9)$ days in 2016, respectively $(p=0.0001)$.

\section{Approach sites and complications of ECMO}

Table 2 shows the approach sites and complications of ECMO. A drainage cannula was inserted in the femoral vein in all of the patients, and a return cannula was inserted into the right jugular vein in $86 \%$ of patients in 2009. However, in 2016, the approach sites of drainage and return cannulas were markedly changed. Femoral and right jugular veins became used for either drainage or a return cannula. There were no differences in the incidence of complications, such as oxygenator failure, blood clots, cannula-related problems, pump head complications, massive bleeding, hemolysis, and venous thrombosis. There were also no differences in the incidence of adverse events indirectly associated with the ECMO circuit, such as massive bleeding, hemolysis, disseminated intravascular coagulation, and venous thrombus.

\section{Outcomes of patients}

Outcomes of the patients enrolled are shown in Table 3. Ventilator days before ECMO were shortened from 5.0 days (1.0-7.0 days) to 1.0 day (1.0-2.8 days), but this difference was not significant. Total ventilator days were
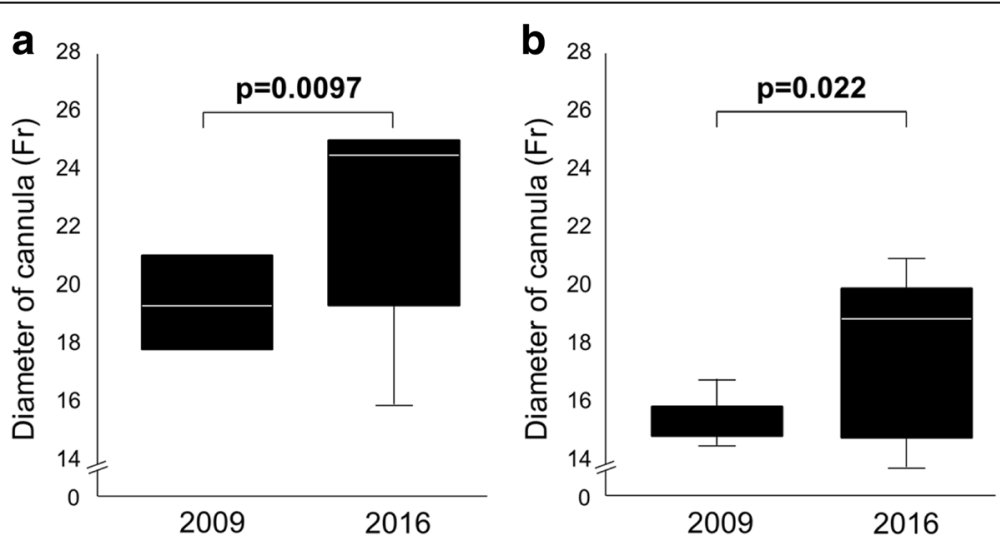

Fig. 1 Diameters of the drainage and return cannulas. Box plot graph showing the diameters of $\mathbf{a}$ the drainage cannula and $\mathbf{b}$ return cannula used in 2009 and 2016. The diameters of both cannulas were significantly larger in 2016 compared with those in 2009 
Table 2 Approach sites and complications of ECMO

\begin{tabular}{|c|c|c|c|}
\hline Year & 2009 & 2016 & $p$ value \\
\hline Approach site of drainage cannula & & & 0.021 \\
\hline Femoral vein & $14(100)$ & $8(57)$ & \\
\hline Right jugular vein & $0(0)$ & $6(43)$ & \\
\hline Approach site of return cannula & & & 0.0498 \\
\hline Femoral vein & $2(14)$ & $6(43)$ & \\
\hline Right jugular vein & $12(86)$ & $6(43)$ & \\
\hline Femoral artery & $0(0)$ & $2(14)$ & \\
\hline \multicolumn{4}{|c|}{ Adverse events directly related to the ECMO circuit } \\
\hline Oxygenator failure & $7(50)$ & $6(43)$ & $>0.99$ \\
\hline \multicolumn{4}{|l|}{ Blood clots } \\
\hline Oxygenator & $3(21)$ & $8(57)$ & 0.12 \\
\hline Other circuit & $1(7)$ & $2(14)$ & $>0.99$ \\
\hline Cannula-related problems & $3(21)$ & $3(21)$ & $>0.99$ \\
\hline Pump head complications & $1(7)$ & $1(7)$ & $>0.99$ \\
\hline \multicolumn{4}{|c|}{ Adverse events indirectly related to the ECMO circuit } \\
\hline \multicolumn{4}{|l|}{ Massive bleeding } \\
\hline Surgical site & $4(29)$ & $3(21)$ & $>0.99$ \\
\hline Upper digestive tract & $4(29)$ & $2(14)$ & 0.65 \\
\hline Cannulation site & $2(14)$ & $2(14)$ & $>0.99$ \\
\hline Pulmonary hemorrhage & $1(7)$ & $0(0)$ & $>0.99$ \\
\hline Hemolysis & $2(14)$ & $1(7)$ & $>0.99$ \\
\hline Disseminated intravascular coagulation & $10(71)$ & $5(36)$ & 0.13 \\
\hline Venous thrombus & $2(14)$ & $4(21)$ & 0.50 \\
\hline
\end{tabular}

ECMO extracorporeal membrane oxygenation not significantly different between the ECMO 2016 group and the ECMO 2009 group. Duration of the use of each circuit was significantly longer in 2016 than in $2009(p=0.0001)$. There was no difference in the number of patients per institute in 2016 compared with 2009. The length of intensive care unit (ICU) stay was significantly longer in 2016 than in 2009 ( $p=0.038)$. The overall survival rate tended to be better in 2016 compared with $2009(p=0.054)$.

\section{Overall survival}

Kaplan-Meier curves show the overall survival rates in each group (Fig. 2). There was a significant difference between the groups $(p=0.007$, log-rank test). Univariate analysis demonstrated that the use of ECMO in 2016 (hazard ratio, 6.33; 95\% confidence interval [CI], 1.35-33.3; $p=0.019$ ) and the maximum SOFA score (hazard ratio, 0.86; 95\% CI, $0.76-0.96 ; p=0.010$ ) were predictive factors of better overall survival. In multivariate analysis, the use of ECMO in 2016 (hazard ratio, 7.25; 95\% CI, $1.35-33.3 ; p=0.021)$ and the maximum SOFA score (hazard ratio, $0.81 ; 95 \% \mathrm{CI}, 0.69-0.95 ; p=0.011$ ) were independent predictive factors of better overall survival (Table 4).

\section{Discussion}

In this study, we showed that the ECMO equipment used for acute respiratory failure in Japan was significantly changed in 2016 compared with 2009. Additionally, the overall survival rate had improved in patients with influenza-associated acute respiratory failure by 2016. Multivariate analysis showed that the use of

Table 3 Outcomes of the patients enrolled

\begin{tabular}{llll}
\hline Year & 2009 & 2016 & $p$ value \\
\hline Ventilator days before ECMO (days) & $5.0(1.0-7.0)$ & $1.0(1.0-2.8)$ & $27(14-38)$ \\
Total ventilator days (days) & $19(9-25)$ & $7.5(4-27)$ & $10.0(8.3-32.5)$ \\
Ventilator-free days (days) & $1.5(0-10.5)$ & $1.0(1.0-2.0)$ & 0.24 \\
Length of ECMO therapy (days) & $8.5(4.5-10.0)$ & $8.5(6.5-14.9)$ & 0.12 \\
Number of circuits used & $2.0(1.3-3.0)$ & $1.0(1.0-1.8)$ \\
Duration of each circuit (days) & $4.0(3.3-4.9)$ & $29(20-41)$ & $24(20-38)$ \\
Number of patients (per institute) & $1.0(1.0-1.0)$ & $41(27-65)$ & 0.08 \\
Length of ICU stay (days) & $17(9-26)$ & $42(23-70)$ \\
Length of ICU stay in survived patients (days) & $24(17-26)$ & $43(37-73)$ \\
Length of hospital stay (days) & $25(12-53)$ & $11(79)$ & 0.14 \\
Length of hospital stay in survived patients (days) & $69(40-77)$ & $11(79)$ & 0.0001 \\
Days alive (days) & $25(14-46)$ & $12(86)$ & 0.037 \\
Overall survival rate & $5(36)$ & $5(36)$ & 0.14 \\
In-hospital survival rate & $5(36)$ & 0.073 \\
$60-$ day survival rate & & 0.054 \\
\hline
\end{tabular}

Data are expressed as median (interquartile) or number (\%)

$E C M O$ extracorporeal membrane oxygenation, $I C U$ intensive care unit, $N A$ not available 


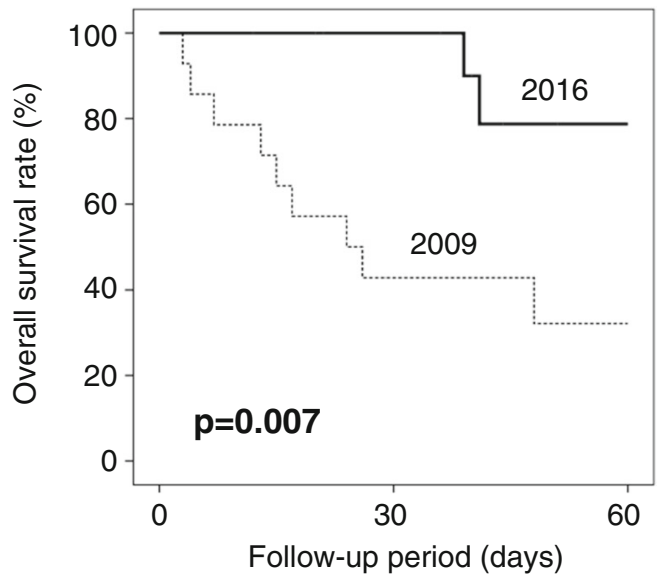

Number at risk

$\begin{array}{llcl}2016 & 14 & 11 & 5 \\ 2009 & 14 & 5 & 3\end{array}$

Fig. 2 Kaplan-Meier curves for the overall survival rates. Kaplan-Meier curves showing the overall survival rates in each group. The thick solid line indicates the patients in 2016, and the narrow dotted line indicates the patients in 2009. There was a significant difference between the groups $(p=0.007)$

ECMO in 2016 was an independent predictive factor for a favorable survival.

Takeda et al. showed that the survival rate of patients with 2009 H1N1 influenza-associated respiratory failure managed with ECMO was limited to 36\% [4]. They also found that the majority of patients suffered from adverse events associated with the use of ECMO. Previous studies from Europe and Oceania showed the benefit of ECMO for influenza-associated acute respiratory failure [7]. The survival rates in patients with 2009 H1N1 influenza-associated respiratory failure managed with ECMO were $92 \%$ in Sweden [6], 76\% in the UK [5], 70\% in Australia and New Zealand [8], 68\% in Italy [9], and 56\% in France [10]. Despite the variation in survival rate according to the country, the survival rates in these countries were always better than that in Japan. A recent meta-analysis regarding the benefit of ECMO for influenza-associated acute respiratory failure demonstrated the worst mortality in Japan of $65 \%$ compared with the other 12 countries included in this meta-analysis [11]. This finding might be partially explained by the insufficient knowledge and skill in Japan in 2009 regarding ECMO equipment and the relevant physiology.

Based on the insufficient survival rate in 2009, the ECMO project was established in Japan to improve the survival rate of influenza-associated respiratory failure. The educational activity by the ECMO project during these years included the lecture regarding physiology of ECMO, managements of bleeding, coagulation, infection and sedation, selection of pumps, oxygenators and cannulae, and the hands-on simulation for the replacement of oxygenators and total circuits, shift from venovenous to venoarterial ECMO, priming of circuits, and fixing mechanical problems. Activity and education by the committee of the ECMO project in Japan might have changed the strategy of ECMO use and promoted improvement of ECMO management, and consequently, the survival rate in patients with influenza-associated acute respiratory failure had improved in 2016. This was partly reflected by changes in oxygenators and pumps shifting to the long-term durability models, diameters of cannulas shifting to a larger size, and the duration of each circuit use becoming longer. In addition, the number of adverse events was similar in 2009 and 2016 despite the longer

Table 4 Univariate and multivariate analyses for better in-hospital and out-of-hospital overall survival

\begin{tabular}{|c|c|c|c|c|}
\hline Variable & $\beta$ & $\mathrm{HR}$ & $(95 \% \mathrm{Cl})$ & $p$ value \\
\hline \multicolumn{5}{|l|}{ Univariate analysis } \\
\hline Use of ECMO in 2016 & 1.85 & 6.33 & $(1.35-33.3)$ & 0.019 \\
\hline Baseline $\mathrm{PaO} 2 / \mathrm{FlO} 2 \mathrm{Baseline} \mathrm{PaO} 2 / \mathrm{FlO} 2$ & 0.05 & 1.05 & $(0.98-1.11)$ & 0.15 \\
\hline Lowest $\mathrm{PaO} 2 / \mathrm{FIO} 2$ Lowest $\mathrm{PaO} 2 / \mathrm{FIO} 2$ & 0.03 & 1.03 & $(0.98-1.08)$ & 0.27 \\
\hline Highest PEEP $(\mathrm{cmH} 2 \mathrm{O})$ Highest PEEP $(\mathrm{cmH} 2 \mathrm{O})$ & -0.07 & 0.93 & $(0.85-1.02)$ & 0.12 \\
\hline Maximum SOFA score & -0.15 & 0.86 & $(0.76-0.96)$ & 0.010 \\
\hline Use of peramivir & 0.81 & 2.25 & $(0.68-7.14)$ & 0.18 \\
\hline Use of oseltamivir & -0.85 & 0.43 & $(0.12-1.47)$ & 0.18 \\
\hline Use of APRV & -0.36 & 0.70 & $(0.18-2.63)$ & 0.60 \\
\hline Size of drainage cannula & -0.16 & 0.85 & $(0.43-1.69)$ & 0.65 \\
\hline Size of return cannula & 0.20 & 1.22 & $(0.57-2.63)$ & 0.60 \\
\hline \multicolumn{5}{|l|}{ Multivariate analysis } \\
\hline Use of ECMO in 2016 & 1.98 & 7.25 & $(1.35-33.3)$ & 0.021 \\
\hline Maximum SOFA score & -0.21 & 0.81 & $(0.69-0.95)$ & 0.011 \\
\hline
\end{tabular}

$H R$ hazard ratio, $\mathrm{Cl}$ confidence interval, ECMO, extracorporeal membrane oxygenation, PaO2/FIO2 partial pressure of arterial oxygen/fraction of inspiratory oxygen ratios, PEEP positive end-expiratory pressure, SOFA sequential organ failure assessment, APRV airway pressure release ventilation 
duration of each circuit, which might have associated with the improved management of ECMO.

Although the severity of an H1N1 influenza infection that occurred in Mexico and the USA in 2009 was similar to that of seasonal influenza, many patients developed severe respiratory failure that was not typical of conventional seasonal influenza [4]. Our study showed that the severity of influenza-associated acute respiratory failure in Japan in 2016 was similar to that of in 2009 according to the APACHE II score and predicted death rate. Despite the similar severity, we could have significantly improved the survival rate. Recent advances in technology (e.g., biocompatible artificial membranes, heparin-coated circuits, and smaller devices), and network organization with referral ECMO centers have contributed to the dramatic increase in the use of ECMO [12, 13]. However, despite these technological improvements, ECMO is still associated with many complications including bleeding, thrombosis, and nosocomial infection [14-16]. Additionally, in-hospital mortality still remains high (35\%-45\%), and long-term impairment in physical/psychological function is also significant $[16,17]$. Considerable investment for high costs of resources, staffing, and training might be important for improving survival rate and reducing complications. Therefore, improvement in overall survival without any increase in complications observed in this study was impressive. Although this improvement in overall survival might have been associated with an application of ECMO in milder cases, multivariate analysis after adjustment for the SOFA score discounted this possibility.

Baseline and lowest $\mathrm{PaO}_{2} / \mathrm{F}_{\mathrm{I}} \mathrm{O}_{2}$ ratios were higher in 2016 than in 2009, suggesting better oxygenation and lower severity status of the enrolled patients in 2016. In addition, ECMO-associated equipment has been improved in 2016. However, the length of ICU stay was significantly longer in 2016, which was likely to be associated with the improved ability of longer management of ECMO with smaller number of complications.

Bleeding is a serious complication that is associated with ECMO and occurs in approximately $20 \%$ of patients [18, 19]. The main mechanisms of bleeding include excessive anticoagulation, thrombocytopenia, and consumption of coagulation factors. Use of ECMO circuits time-dependently activates plasma metalloproteinase-2, a pathway of platelet aggregation, with a subsequent increase in plasma soluble P-selectin concentrations [20]. The resultant platelet dysfunction persists after repeated transfusions of platelets to maintain sufficient platelet counts. Acquired von Willebrand syndrome could also be a complication associated with ECMO. This is characterized by loss of the high molecular weight of von Willebrand factor as a result of shear stress, which impairs binding of von Willebrand factor to platelets [21]. Therefore, adequate selection of ECMO equipment is essential to minimize the shear stress. A shift to the long-term durability models of oxygenators and pumps and to the larger size of diameter of cannulas could have contributed to the reduction in platelet dysfunction, resulting in the longer durability of each circuit in our study.

Previous studies have suggested that centralization of ECMO use to expert referral centers may contribute to improved survival [22, 23]. Propensity score matching analysis suggested that transfer to an ECMO center was associated with a $50 \%$ reduction in mortality [5]. Bryner et al. suggested that ECMO centers experiencing more than 30 cases/year were consistently associated with better survival [24]. However, concluding that use of ECMO itself improves survival is difficult because ECMO centers are usually centers of excellence, which can provide better overall intensive care [25]. No definite conclusion can be made because of the lack of randomized, controlled trials. However, adequate use of ECMO after the onset of acute respiratory failure can result in improved survival. Although centralization of ECMO use in Japan has been partially promoted, the number of patients per institute has not yet significantly increased.

Despite the similar severity according to the APACHE II score and predicted death rate, baseline $\mathrm{PaO}_{2} / \mathrm{F}_{\mathrm{I}} \mathrm{O}_{2}$ ratios before and during ventilation were significantly different in both groups. Higher $\mathrm{PaO}_{2} / \mathrm{F}_{\mathrm{I}} \mathrm{O}_{2}$ ratio in 2016 may have associated with less severity in lung injury or early initiation of ECMO. The indication criteria of ECMO are generally considered as patients with mortality risk of 50 to 80\%, according to the Extracorporeal Life Support Organization Guidelines [26]. However, the use of ECMO can be associated with various severities of complications, and permissive hypoxemia is an emerging concept in which a lower level of arterial oxygenation can be accepted to avoid the harmful effects of high concentration of inspired oxygen and invasive mechanical ventilation [27]. Therefore, the indication criteria of ECMO might be reconsidered in the future studies.

Our study includes several potential limitations. First, this study was based on surveillance, which did not cover all patients who received ECMO. Second, several clinical items were not completely included because of the retrospective design. Further prospective studies are necessary for confirming the data observed in this study.

\section{Conclusions}

In conclusion, the surveillance in Japan showed that the overall survival rate was significantly improved in patients with influenza-associated acute respiratory failure, who were managed with ECMO in 2016 compared with those in 2009. The procedures of respiratory 
management using ECMO have significantly changed in 2016. Adequate use of ECMO equipment and promoting better understanding of ECMO physiology in medical staff might have been associated with the improved survival rate in patients with influenza-associated acute respiratory failure in Japan.

\section{Abbreviations}

APACHE: Acute physiology and chronic health evaluation; Cl: Confidence interval; $\mathrm{ECMO}$ : Extracorporeal membrane oxygenation; $\mathrm{F}_{1} \mathrm{O}_{2}$ : Fraction of inspiratory oxygen; $\mathrm{PaO}_{2}$ : Partial pressure of arterial oxygen; SOFA: Sequential organ failure assessment

\section{Acknowledgements}

We thank the following institutes included in the ECMO registry (ecmokokyu-jsicm@jrcm.in.arena.ne.jp) for data collection of this study: Chiba University, Hiroshima General Hospital, Japanese Red Cross, Musashino Hospital, Jichi Medical University, Kobe University, Kurume University, Maebashi Red Cross Hospital, Nagasaki University, National Center for Global Health and Medicine, Niigata University, Nippon Medical School, Osaka City University, Osaka Women's and Children's Hospital, Tokyo Metropolitan Bokutoh Hospital, Tokyo Metropolitan Children's Medical Center, and Tsukuba University.

We thank Ellen Knapp, PhD, from Edanz Group (www.edanzediting.com/ac) for editing a draft of this manuscript.

\section{Funding}

This work was supported by a Japan Society for the Promotion of Science (JSPS) KAKENHI Grant (Numbers JP 16K09541, 17K11573), Strategic Information and Communications R\&D Promotion Programme (SCOPE), and the Japan Agency for Medical Research and Development (AMED).

\section{Availability of data and materials}

The datasets during and/or analyzed during the current study are available from the corresponding author on reasonable request.

\section{Authors' contributions}

SO collected and analyzed the data and drafted the manuscript. NS supervised the study and revised the manuscript. SN, ON, and ST designed and organized the study, helped with data collection, and revised the manuscript. All authors read and approved the final manuscript.

\section{Ethics approval and consent to participate}

This study was approved by the ethical committee in Hiroshima University with the approval number of E-390-1. Each institute obtained institutional ethics approval and consent to participate.

\section{Consent for publication}

Informed consents of patients for publication were obtained by the opt-out procedure, according to the procedure described in the study protocol (E-390-1).

\section{Competing interests}

The authors declare that they have no competing interests.

\section{Publisher's Note}

Springer Nature remains neutral with regard to jurisdictional claims in published maps and institutional affiliations.

\footnotetext{
Author details

'Department of Emergency and Critical Care Medicine, Graduate School of Biomedical and Health Sciences, Hiroshima University, 1-2-3 Kasumi, Minami-ku, Hiroshima 734-8551, Japan. ${ }^{2}$ Department of Critical Care and Anesthesia, National Center for Child Health and Development, Tokyo, Japan. ${ }^{3}$ Department of Anaesthesiology and Critical Care Medicine, Fujita Health University School of Medicine, Aichi, Japan. ${ }^{4}$ Kawaguchi Cardiovascular and Respiratory Hospital, Saitama, Japan.
}

Received: 19 April 2018 Accepted: 12 June 2018

Published online: 11 July 2018

\section{References}

1. Centers for Disease Control and Prevention (CDC). Estimates of deaths associated with seasonal influenza — United States, 1976-2007. MMWR Morb Mortal Wkly Rep. 2010;59:1057-62.

2. Fan E, Pham T. Extracorporeal membrane oxygenation for severe acute respiratory failure: yes we can! (but should we?). Am J Respir Crit Care Med. 2014;189:1293-5.

3. Cooper DJ, Hodgson CL. Extracorporeal membrane oxygenation rescue for H1N1 acute respiratory distress syndrome: equipoise regained. Am J Respir Crit Care Med. 2013:187:224-6.

4. Takeda S, Kotani T, Nakagawa S, Ichiba S, Aokage T, Ochiai R, Taenaka N, Kawamae K, Nishimura M, Ujike Y, Tajimi K. Extracorporeal membrane oxygenation for 2009 influenza a (H1N1) severe respiratory failure in Japan. J Anesth. 2012;26:650-7.

5. Noah MA, Peek GJ, Finney SJ, Griffiths MJ, Harrison DA, Grieve R, Sadique MZ, Sekhon JS, MCAuley DF, Firmin RK, Harvey C, Cordingley JJ, Price S, Vuylsteke A, Jenkins DP, Noble DW, Bloomfield R, Walsh TS, Perkins GD, Menon D, Taylor BL, Rowan KM. Referral to an extracorporeal membrane oxygenation center and mortality among patients with severe 2009 influenza a (H1N1). JAMA. 2011;306:1659-68.

6. Holzgraefe B, Broome M, Kalzen H, Konrad D, Palmer K, Frenckner B. Extracorporeal membrane oxygenation for pandemic H1N1 2009 respiratory failure. Minerva Anestesiol. 2010:76:1043-51.

7. Zangrillo A, Biondi-Zoccai G, Landoni G, Frati G, Patroniti N, Pesenti A, Pappalardo F. Extracorporeal membrane oxygenation (ECMO) in patients with H1N1 influenza infection: a systematic review and meta-analysis including 8 studies and 266 patients receiving ECMO. Crit Care. 2013;17:R30.

8. Davies A, Jones D, Bailey M, Beca J, Bellomo R, Blackwell N, Forrest P, Gattas D, Granger E, Herkes R, Jackson A, McGuinness S, Nair P, Pellegrino V, Pettila V, Plunkett B, Pye R, Torzillo P, Webb S, Wilson M, Ziegenfuss M. Extracorporeal membrane oxygenation for 2009 influenza a (H1N1) acute respiratory distress syndrome. JAMA. 2009:302:1888-95.

9. Patroniti N, Zangrillo A, Pappalardo F, Peris A, Cianchi G, Braschi A, lotti GA, Arcadipane A, Panarello G, Ranieri VM, Terragni P, Antonelli M, Gattinoni L, Oleari F, Pesenti A. The Italian ECMO network experience during the 2009 influenza a (H1N1) pandemic: preparation for severe respiratory emergency outbreaks. Intensive Care Med. 2011;37:1447-57.

10. Roch A, Lepaul-Ercole R, Grisoli D, Bessereau J, Brissy O, Castanier M, Dizier S, Forel JM, Guervilly C, Gariboldi V, Collart F, Michelet P, Perrin G, Charrel R, Papazian $L$. Extracorporeal membrane oxygenation for severe influenza a (H1N1) acute respiratory distress syndrome: a prospective observational comparative study. Intensive Care Med. 2010:36:1899-905.

11. Sukhal S, Sethi J, Ganesh M, Villablanca PA, Malhotra AK, Ramakrishna H. Extracorporeal membrane oxygenation in severe influenza infection with respiratory failure: a systematic review and meta-analysis. Ann Card Anaesth. 2017;20:14-21.

12. MacLaren G, Combes A, Bartlett RH. Contemporary extracorporeal membrane oxygenation for adult respiratory failure: life support in the new era. Intensive Care Med. 2012;38:210-20.

13. Blum JM, Lynch WR, Coopersmith CM. Clinical and billing review of extracorporeal membrane oxygenation. Chest. 2015;147:1697-703.

14. Schmidt M, Zogheib E, Roze H, Repesse X, Lebreton G, Luyt CE, Trouillet JL, Brechot N, Nieszkowska A, Dupont H, Ouattara A, Leprince P, Chastre J, Combes A. The PRESERVE mortality risk score and analysis of long-term outcomes after extracorporeal membrane oxygenation for severe acute respiratory distress syndrome. Intensive Care Med. 2013;39:1704-13.

15. Cooper E, Burns J, Retter A, Salt G, Camporota L, Meadows Cl, Langrish CC, Wyncoll D, Glover G, loannou N, Daly K, Barrett NA. Prevalence of venous thrombosis following Venovenous extracorporeal membrane oxygenation in patients with severe respiratory failure. Crit Care Med. 2015;43:e581-4.

16. Zangrillo A, Landoni G, Biondi-Zoccai G, Greco M, Greco T, Frati G, Patroniti $\mathrm{N}$, Antonelli M, Pesenti A. Pappalardo F. A meta-analysis of complications and mortality of extracorporeal membrane oxygenation. Crit Care Resusc. 2013;15:172-8.

17. Rozencwajg S, Pilcher D, Combes A, Schmidt M. Outcomes and survival prediction models for severe adult acute respiratory distress syndrome treated with extracorporeal membrane oxygenation. Crit Care. 2016;20:392. 
18. Munshi L, Telesnicki T, Walkey A, Fan E. Extracorporeal life support for acute respiratory failure. A systematic review and metaanalysis. Ann Am Thorac Soc. 2014;11:802-10.

19. Ried M, Bein T, Philipp A, Muller T, Graf B, Schmid C, Zonies D, Diez C, Hofmann HS. Extracorporeal lung support in trauma patients with severe chest injury and acute lung failure: a 10-year institutional experience. Crit Care. 2013;17:R110

20. Cheung PY, Sawicki G, Salas E, Etches PC, Schulz R, Radomski MW. The mechanisms of platelet dysfunction during extracorporeal membrane oxygenation in critically ill neonates. Crit Care Med. 2000;28:2584-90.

21. Heilmann C, Geisen U, Beyersdorf F, Nakamura L, Benk C, Trummer G, Berchtold-Herz M, Schlensak C, Zieger B. Acquired von Willebrand syndrome in patients with extracorporeal life support (ECLS). Intensive Care Med. 2012; 38:62-8.

22. Barbaro RP, Odetola FO, Kidwell KM, Paden ML, Bartlett RH, Davis MM, Annich GM. Association of hospital-level volume of extracorporeal membrane oxygenation cases and mortality. Analysis of the extracorporeal life support organization registry. Am J Respir Crit Care Med. 2015;191:894-901.

23. Peek GJ, Mugford M, Tiruvoipati R, Wilson A, Allen E, Thalanany MM, Hibbert CL, Truesdale A, Clemens F, Cooper N, Firmin RK, Elbourne D. Efficacy and economic assessment of conventional ventilatory support versus extracorporeal membrane oxygenation for severe adult respiratory failure (CESAR): a multicentre randomised controlled trial. Lancet. 2009;374:1351-63.

24. Bryner B, Cooley E, Copenhaver W, Brierley K, Teman N, Landis D, Rycus P, Hemmila M, Napolitano LM, Haft J, Park PK, Bartlett RH. Two decades' experience with interfacility transport on extracorporeal membrane oxygenation. Ann Thorac Surg. 2014;98:1363-70.

25. Wallace DJ, Milbrandt EB, Boujoukos A. Ave, CESAR, morituri te salutant! (hail, CESAR, those who are about to die salute you!). Crit Care. 2010;14:308.

26. Extracorporeal Life Support Organization (ELSO). General Guidelines for all ECLS Cases. https://www.elso.org/Portals/0/ ELSO\%20Guidelines\%20General\%20All\%20ECLS\%20Version\%201_4.pdf. Accessed 30 May 2018.

27. Gilbert-Kawai ET, Mitchell K, Martin D, Carlisle J, Grocott MP. Permissive hypoxaemia versus normoxaemia for mechanically ventilated critically ill patients. Cochrane Database Syst Rev. 2014;5:CD009931.

\section{Ready to submit your research? Choose BMC and benefit from:}

- fast, convenient online submission

- thorough peer review by experienced researchers in your field

- rapid publication on acceptance

- support for research data, including large and complex data types

- gold Open Access which fosters wider collaboration and increased citations

- maximum visibility for your research: over $100 \mathrm{M}$ website views per year

At BMC, research is always in progress.

Learn more biomedcentral.com/submissions 